\title{
Metrópoles beduínas
}

\author{
Guilherme Kujawski*
}

Resumo A diferença entre práticas habitacionais de povos sedentários e nômades deveria ser analisada mais detidamente pelos estudos de urbanismo. Apesar da condição estática das cidades modernas, a relocalização estrutural tem sido revisitada, em maior escala, não apenas pela arquitetura radical. Mais do que invencionices de artistas, a ideia de avivar cidades, tornado-as elas próprias sujeitos nômades, vem se destacando da fantasia e adquirindo, literalmente, características reais. Apesar de exemplos esparsos, é possível construir uma narrativa que se inicia com imagens procedentes da cultura popular, percorre por projetos de arquitetos visionários da década de 1960 e termina com um caso concreto na Europa do Norte.

Palabras-clave: nomadismo, arquitetura radical, mudanças climáticas.

\section{Bedouin Metropolis}

\begin{abstract}
The difference between the housing practices of sedentary and nomadic peoples should be analyzed more closely by urban studies. Despite the static condition of modern cities, structural relocation has been revisited, on a larger scale, not only by radical architecture. More than inventions of artists, the idea of enliven cities, making themselves nomadic subjects, has been detached from fantasy and literally acquired real characteristics. Despite sparse examples, it is possible to construct a narrative that begins with images from popular culture, goes through projects of visionary architects of the 1960s and ends with a concrete case in Northern Europe.
\end{abstract}

Keywords: nomadism, radical architecture, climate change.

\section{Metrópolis beduinas}

Resumen La diferencia entre prácticas habitacionales de pueblos sedentarios y nómadas debería ser analizada más detenidamente por los estudios de urbanismo. A pesar de la condición estática de las ciudades modernas, la relocalización estructural ha sido revisitada, en mayor escala, no sólo por la arquitectura radical. Más que invenciones de artistas, la idea de avivar ciudades, tornadas ellas propias nómadas, viene destacándose de la fantasía y adquiriendo, literalmente, características reales. A pesar de ejemplos esparcidos, es posible construir una narrativa que se inicia con imágenes procedentes de la cultura popular, recorre por proyectos de arquitectos visionarios de la década de 1960 y termina con un caso concreto en la Europa del Norte.

Palabras clave: nomadismo, arquitectura radical, cambios climáticos. 
$-0$

povos nômades e sedentários foram, durante séculos, os maiores protagonistas da história da humanidade. O contraste entre as hordas sem habitação fixa e os habitantes das comunidades autogovernadas favoreceu o surgimento de diversas correntes de pensamento que exaltavam as cidades, principalmente sua qualidade de reduto seguro contra a violência de bárbaros invasores. Neste sentido, as cidades são o sinônimo de solidariedade, saneamento básico e leis justas, elementos estranhos ao universo formado, por exemplo, pelo agrupamento de tendas circulares (yurt), segundo a visão dos povos conquistados. Na verdade, os nômades asiáticos, principalmente os mongóis, portavam um sofisticado aparato cultural, tanto que suas idealizações arquitetônicas resultaram na primeira cidade nômade que se têm notícia, conhecida pelos historiadores como Urga, que mais tarde se tornou a capital da Mongólia, Ulaanbaatar [anglicizado como Ulan Bator] (MAJER \& TELEKI, 2006: 21). Mas a pujança das cidades construídas por povos agricultores eliminou definitivamente das ordens culturais a figura do nomadismo habitacional e, durante o Renascimento, as primeiras cidades-estado helênicas foram o modelo ideal para as civitas Dei, jurisdições propícias para o desenvolvimento humano. A utopia renascentista da cidade perfeita sobreviveu às cidades industriais modernas, mas foi substituída recentemente por um nomadismo atávico. Um novo impulso de mobilidade franqueado pelas novas tecnologias gerou um movimento forte o suficiente para ser chamado de neonomadismo, ${ }^{1}$ o qual foi influenciado, ainda na década de 1960, pelo advento de uma obscura ficção urbana: as cidades móveis.

\section{Nomadismo e individualismo}

A queda da utopia da cidade perfeita, na acepção aristotélica do termo, foi acelerada por movimentos nômades contemporâneos. Os tecno-nômades, mais especificamente, empregam tecnologias de ponta na busca pela mobilidade ideal, mas sem inseri-las dentro de uma ação política coletiva (RUCKER \& SIRIUS \& MU, 1992: 190-191). $\mathrm{O}$ individualismo radical associou-se naturalmente ao neonomadismo tecnicista e encontrou nos Estados Unidos - terra do narcisismo normativo e objeto ideal de análises tocquevillianas - o local perfeito para se desenvolver. Steve Roberts, ainda

* Guilherme Kujawski é Arquiteto e Urbanista, professor da Faculdade de Arquitetura e Urbanismo da Universidade de São Paulo, ORCID <https://orcid.org/00000002-3387-0884>

1 D'ANDREA, Anthony. Neo-Nomadism: A Theory of Post-Identitarian Mobility in the Global Age. Mobilities, v. 1, n. 1, p. 95-119, 2006.

2 Ver detalhes em <https://microship.com>. Acesso em: 10 jan. 2018. no começo da década de 90, vagou por toda a Sillicon Valley com sua Behemoth (sigla de Big, Electronic, Human-Energized Machine, Only Too Heavy), uma bicicletatrailer que gera energia cinética o suficiente para alimentar a bateria de um PC e um primitivo sistema de GPS instalado a bordo. Em 2003, ele construiu um barco de fibra de vidro, equipou-o com material de telemetria e lançou-se no rio Mississippi, realizando sua maior aventura tecno-nômade. O projeto, batizado por Roberts de Microships, ${ }^{2}$ ilustra perfeitamente a inversão das antigas utopias citadinas e o advento de um neonomadismo crítico, um verdadeiro manifesto do desprendimento individual e uma apologia das paragens abertas.

Outro modelo de neonomadismo individualista é proposto no trabalho do artista Michael Rakowitz, autor de PARAsite (RAKOWITZ \& CHRISTOV-BAKARGIEV, 2003), 
projeto que fica situado na intersecção entre arte, arquitetura e contestação social. Seu interesse pelo design de moradias nômades começou durante seus estudos na escola de arquitetura do Massachusetts Institute of Technology (MIT), e foi neste período que viajou para a região de Kerak, Jordânia, com o intuito de pesquisar as tendas de beduínos do deserto que, ao mesmo tempo em que protegem seus moradores dos elementos naturais, canalizam a ventilação de forma aerodinâmica. Ao voltar para Nova York, dois fatos motivaram Rakowitz a criar um dos mais interessantes projetos de nomadismo urbano: a percepção de que muitos sem-teto dormiam ao lado da saída de exaustores e aparelhos de ar-condicionado; e a lei do prefeito Rudolph Giuliani, que obrigou todos os moradores de rua a dormirem em albergues, locais reconhecidamente perigosos. Foi assim que ele passou a confeccionar tendas infláveis que pudessem ser montadas com facilidade e tivessem uma tubulação especial para ser acoplada à saída dos exaustores, criando um sistema próprio de aquecimento. Apesar de seu caráter artístico, o projeto de Rakowitz não tem pretensões estéticas, e sim utilitaristas e políticas, ao circunscrever as leis municipais que proíbem a permanência de nômades urbanos em logradouros públicos.

O neonomadismo individualista chegou a ser considerado seriamente por vários grupos de arquitetos revolucionários. O trailer não seria apenas mais um sonho de consumo da família norte-americana do período pós-guerra - sonho ironizado de forma definitiva no filme The Long, Long Trailer (1954), estrelado pela a comediante Lucille Ball -, mas sim o leitmotif para a formação de uma verdadeira cultura neonomade. Aos poucos, o vetor do movimento passou a apontar para a Europa e perder os matizes individualistas do tipo caracol, adquirindo o porte de estruturas comunitárias, mas ainda infactíveis no mundo real.

\section{Perspectivas ficcionais}

Que a ficção urbana seja uma esfera de certa forma encampada pela arquitetura, é na ficção cultural (literatura, cinema) que vamos nos deparar de maneira mais propícia com as cidades antropomórficas, noção pouco afeita ao senso comum. Grosso modo, muitos escritores inventam cidades imaginárias para reforçar o simbolismo quase místico que antecede o soerguimento de uma polis. A intenção não é demonstrar que o ato da fundação de uma cidade seja equiparável à poética do fazer artístico, e sim o caráter subjetivo e imaginativo do processo arquitetônico. Mas a aplicação literal de membros de sustentação a um coletivo urbanístico, ou mesmo a simples incorporação de aspectos fisiológicos a uma formação metropolitana exige um esforço quase demiúrgico de pensamento. A transformação de cidades inteiras em entidades autônomas e antropomórficas é um tema pouco explorado no campo da arquitetura, devido ao risco de se imputar a um imóvel a qualidade de um móvel: um erro categorial. Todavia, nas belas-artes - mais precisamente na ficção especulativa - não existe o receio de se incorrer no oximoro.

\section{Antropomorfismos}

No ano de 2008, o personagem Stu Cole tenta administrar honestamente a casa noturna Anesthesia na cidade de São Francisco, EUA. Mas as gangues de mafiosos que povoam as ruas representam um entrave ao seu negócio, já que não medem esforços para dominar a população e controlar o que resta do poder central. Certo 
3 Ver detalhes em <http://exalted. xi.co.nz/wiki/wiki.pl?Miedvied/ Omphalan> Acesso em: 10 jan. 2018. dia, um homem de óculos escuros, espécie de golem punk, entra em seu bar pedindo ajuda para "eliminar o mal". O personagem não é nada mais nada menos do que a própria encarnação da cidade de São Francisco, um avatar da metrópole que conseguiu literalmente se destacar do concreto e caminhar com seus próprios pés. A história de City Come a-Walkin' (SHIRLEY, [1980] 2014) é o embrião do que viria a ser a literatura cyberpunk, uma vertente da ficção científica capitaneada por um grupo de futuristas cansado de se identificar com antigas utopias da Golden Age. Um futuro maravilhoso definitivamente não faz parte do rol das confabulações criadas por eles. De qualquer forma, o ponto alto do livro de Shirley é a personagem City, a materialização da cidade em um corpo implacável que luta contra a corrupção e o crime, o que o faz parecer um paladino cristão guiado pela noção agostiniana de que a cidade é a residência do homem inerentemente pecaminoso. Para City, políticos, empresários, policiais, banqueiros, ou seja, todos os representantes da estrutura municipal precisam ser erradicados como insetos, de preferência com um banho de sangue. Mas, para que isso aconteça, a cidade deve se tornar uma criatura, um corpo metonímico que espreita seus próprios conteúdos nas esquinas.

A fábula de Shirley reflete a tendência neonômade ao tratar a cidade como uma entidade moral, e não como um mero objeto físico, ou o resultado de ações e preferências humanas. Se a personificação de uma suprema ordem social e cultural neutraliza o dualismo entre indivíduo e sociedade, chegando a eliminar a própria noção de sujeito, o que aconteceria se a entidade que a personifica fosse a própria cidade? Neste caso, ela poderia ser antropomorficamente transformada em um juiz moral, como a personagem City de Shirley. No universo dos RPGs (Role Playing Games) o tópico da cidade personificada é relativamente bem explorado. Em Exalted, ${ }^{3}$ um RPG criado por estudantes universitários, a personagem Omphalan, também conhecida pelo aposto "a Cidade que Anda", caminha pelas paisagens fantásticas da "burocracia celestial", concentrando em seu bojo todos os gabinetes de outras localidades. A incorporação de vários atributos, como a capacidade de instilar obediência e delegar autoridade, permite que Omphalan seja a epítome de uma municipalidade moral com licença para "caçar burocratas e punir os corruptos". Apesar da puerilidade narrativa, a história da personagem Omphalan é uma tradução da história de City e mostra como a contraposição homem/cidade recebeu uma carga fatal de moralismo, ao menos no campo da ficção.

\section{O castelo metonímico}

O anime Howl's Moving Castle (O Castelo Animado, 2004), dirigido por Hayao Miyazaki e adaptado de uma história da escritora britânica Diana Wynne Jones, também explora o tema da animação de estruturas imóveis que a princípio são inanimadas - neste caso, o castelo do feiticeiro Howl. No portal de entrada do castelo há um tipo de disco de Newton com quatro cores que funciona como um "menu" de acesso para quatro planos: o idílico interior do país de Gales onde o feiticeiro viveu sua infância; um sobrado na área costeira, onde ele comercializa seus serviços místicos; uma casa na capital do reino fantástico de Ingary e um castelo andarilho que parece ser a conjunção de Gormenghast - o castelo-cidade concebido pelo escritor inglês Mervyn Peake - com uma das invenções improváveis do ilustrador William Heath Robinson. 
4 ANDERSON, Darran. The Prophetic Side of Archigram. CityLab, 2017. Disponível em: $<$ https://www.citylab.com/design/2017/11/the-prophetic-sideof-archigram/545759/>. Acesso em: 25 janeiro 2018.
No desenho onírico e antibélico de Miyazaki, não fica claro se o castelo é um portal para os planos adjacentes ou se ele realmente os incorpora. Em certos momentos, há a sugestão de que os ambientes citadinos estão contidos metonimicamente no interior do castelo, já que a única via de acesso a eles é um portal localizado na cozinha, onde reside Calcifer, um demônio do fogo que movimenta toda a estrutura. Tanto em Howl's Moving Castle como em City Come a-Walkin', a cidade é incorporada numa entidade que caminha "em direção à vida", e que, segundo a precisa descrição do escritor austríaco Robert Musil sobre o ato de caminhar, "ergue o centro de gravidade, empurra-o para diante e o deixa cair" (MUSIL, 1980: 94). O clima retrofuturista do desenho animado associa todas as formas de mobilidade não com as abundantes máquinas voadoras vitorianas, mas com um trôpego castelo medievo que se desloca com suas enormes garras mecânicas. Mas um pouco de receio dessa projeção para frente, ou simplesmente o espanto por fazer isso, e o castelo já não pode ficar mais em pé, parafraseando o próprio Musil. Não seria então mais Calcifer o princípio motor do castelo de Howl, mas simplesmente a sua fascinação quase infantil por sua capacidade de caminhar, tendo sempre em vista o risco da queda.

\section{Radicalismos urbanos}

Assim feita a nossa incursão por expressões da cultura popular sobre o tema, faz-se necessário aproximá-lo mais para o domínio da arquitetura e urbanismo, mesmo que sob a égide de radicalismos conceituais. Grupos de arquitetos vanguardistas do período pós-guerra, como o Team $\mathrm{X}$, por exemplo, criticavam a fragmentação das cidades em zonas hierarquizadas (casas, ruas, distritos, cidade) e, em troca, prescreveram a noção da cidade orgânica. O grupo Superstudio, formado por jovens arquitetos de Florença, deu um passo a frente e propôs a transformação utópica da vida por meio de estruturas móveis, flexíveis e infláveis. Já o GEAM (Groupe d'Espace et d'Architecture Móbile), tinha como meta aplicar os princípios de mobilidade à arquitetura, pesquisando estruturas espaciais (megaestruturas) que pudessem ser completamente transformadas. Mas foi o Archigram, grupo de arquitetos atuante de 1961 a 1974, conhecido por incorporar ficção científica e cultura popular em seus projetos, que sistematizou de forma original (porém metafórica) o conceito da "cidade móvel" (RILEY, 2002), uma investigação profética sobre a crescente mobilidade dos neonomades (também chamados de "trabalhadores-viajantes") e como as cidades cada vez mais dependem de seus ambientes circundantes. ${ }^{4}$

\section{Cidades flutuantes}

Não apenas um senso de conquista do desconhecido, mas as visões das vastas distâncias evoluíram apesar dos avanços tecnológicos que vêm aprimorando a fixação dos indivíduos em sedes, escritórios, tribunais, oficinas, espaços públicos e privados. Os postulados arquitetônicos, a partir dos anos 1960, se desataram de antigos dogmas, e começaram a incluir elementos ficcionais, obrigando os projetos a fluírem, inflarem, respirarem, expandirem-se e multiplicarem-se. O modelo tecnológico das estruturas móveis surgiu como contraponto aos conceitos mecânicos de ordem, que não levavam em consideração o fato de que as cidades são mais do que a soma de suas partes: habitações, espaços públicos e indivíduos. As partes compõem um todo não absoluto e dependem da mobilidade para se unirem e se desconectarem de acordo com os princípios que regem os organismos complexos. Em 1914, o arquiteto italiano 
5SANT'ELIA, Antonio. Manifesto of Futurist Architecture 1914. In APOLLONIO, 1973: 160-172
6 Ver, por exemplo, a surpreendente semelhança entre os "casulos" estampados nas colagens de Cities: Moving, de 1964, e os módulos da Estação de Pesquisa Halley na Antártica (mais especificamente, o Haley VI), projetados 40 anos depois pelo escritório de arquitetura Hugh Broughton Architects. Mais detalhes em British Antarctic Survey <https:// www.bas.ac.uk/polar-operations/ sites-and-facilities/facility/halleys. Acesso 10 Jan. 2018.

7 Ver mais detalhes em <http:// www.archigram.net/projects_pages/walking_city.html> Acesso em: 10 jan. 2018.
Antonio Sant' Elia proclamou em seu manifesto: "Devemos refazer as cidades numa linha de produção e reinventá-las com partes constituintes dinâmicas. A casa futurista assemelha-se a uma máquina gigante" ${ }^{5}$ A noção de cidade dinâmica dos futuristas foi sucedida por outras noções de mobilidade; mas antes de "caminhar», as cidades deveriam «flutuar», passando pelos obrigatórios estágios evolutivos dos viventes.

A ideia não é nova. De acordo com a história bíblica, Noé foi convocado por Deus para construir uma arca que pudesse abrigar, além de sua família, representantes de animais (e plantas) de todo planeta. Segundo as precisas medidas inscritas no Velho Testamento, a arca que salvou seus integrantes do dilúvio comportava dimensões nada desprezíveis, podendo ser associada não apenas a uma cidade, mas a uma vasta região. Em termos reais, vários arquitetos ousaram desenvolver projetos concretos de cidades flutuantes, a começar por Kenzo Tange, que propôs reconstruir Tóquio sobre uma série de plataformas marítimas (RILEY, Ibid:49). Nos Estados Unidos, Buckminster Fuller imaginou cidades flutuantes com capacidade para 5.000 pessoas e, para realizá-las, elaborou o projeto das superestruturas construídas com elementos pré-fabricados sobre plataformas de aço - um conjunto que poderia ser montado em canteiros navais e depois transportado por rebocadores em direção ao mar aberto. Uma proposta mais crítica do que realista foi lançada por Hans Hollein que, em 1964, colou a imagem de um porta-aviões sobre a foto de uma paisagem austríaca (Aircraft Carrier City in Landscape), uma sugestão de que as cidades poderiam estar situadas em qualquer lugar.

\section{Cidades andarilhas}

Um dos arquitetos do grupo Archigram (fusão das palavras architecture e telegram), Warren Chalk, realizou vários experimentos usando o paradigma da cápsula espacial que, por sua vez, serviu de inspiração para que David Greene, outro integrante, criasse o projeto Living-Pod, em que pernas ajustáveis são anexadas na base de uma cápsula central. Os módulos avulsos poderiam ser acoplados uns aos outros por meio de sistemas de plug-in, retomando o efeito multiplicativo das megaestruturas e a capacidade articular de macromateriais. Mas a semelhança das pernas mecânicas com suas contrapartes humanas é, sem dúvida, o fator mais inquietante do projeto. Ao avaliar as grandes possibilidades do Living-Pod, um outro integrante do grupo, Ron Herron, levou ao paroxismo o conceito da cidade andarilha e revolucionou a relação entre movimento e permanência das estruturas urbanas. A imagem de seu veículo habitacional mestre é o imperativo máximo de um construto arquitetônico nômade, que até hoje exerce inspirações, consciente ou inconscientemente. ${ }^{6}$

Um dos integrantes do grupo levou ao pé da letra a ideia de se construir uma cidade andarilha. O projeto The Walking City, ${ }^{7}$ de Ron Herron, previa adaptar pernas robóticas nas unidades de habitação de Le Corbusier, uma construção modular com capacidade de abrigar duas mil pessoas que fazia parte do plano de reconstrução que o governo francês elaborou logo após a Segunda Guerra Mundial. Os módulos, por sua vez, poderiam se deslocar, como uma caravana circense, em direção a estações de substituição de moradores e se acoplar em áreas específicas de evacuação de dejetos urbanos. O plano visionário de Herron também previa a união de diversos módulos por meio de corredores retráteis, formando verdadeiros conglomerados sobre regiões terrestres e marítimas. Certamente, a proposta tinha a função de tecer um comentário sobre as 
8STOTT, Rory. A Walking City for the 21st Century. ArchDaily, 2013. Disponível em <https:// www.archdaily.com/443701/awalking-city-for-the-21st-century> Acesso em: 10 jan. 2018.

9 Ver Mortal Engines. In: Wikipedia. [s.l.: s.n.], 2018. Disponível em: <https://en.wikipedia. org/w/index.php?title=Mortal_ Engines\&oldid $=818865844>$. Acesso em: 10 jan. 2018.
10 NILSSON, Kristina L. Place Reinvention by Real Changed Image: The Case of Kiruna's Spectacular Make-over. In NYSETH; VIKEN, 2012, pp. 33-51.

11 FREARSON, Amy. White Arkitekter unveils masterplan for Swedish city relocation. Dezeen, 2014. Vídeo disponível em: <https://www.dezeen. com/2014/06/04/white-arkitetker-the-new-kiruna-city-relocation-sweden/>. Acesso em: 25 janeiro 2018. mudanças drásticas pelas quais as cidades modernas estão sendo submetidas, e não compor uma alteração real das estruturas, mas a sua implementação chegou a ser considerada para uma das unidades de habitação localizada em Marselha. O projeto da cidade nômade, criado em 1964, ou seja, em plena guerra fria, valorizava mais a fantasia do que a prática e fazia mais sentido numa época em que os cenários de áreas devastadas por bombas nucleares ainda estavam frescos na memória popular.

A cidade andarilha de Herron, como dissemos, é um magneto inspirador, inclusive na contemporaneidade, apesar de suas características satíricas. Considere o projeto Very Large Structure $(V L S),{ }_{1}^{8}$ do mestrando espanhol em arquitetura Manuel Dominguez, uma cidade composta por três níveis funcionais, com um comprimento de 560 metros e movida por gigantescas lagartas mecânicas. Por certo o projeto remete às elucubrações de Herron, mas é possível associar o arcabouço programático do estudante espanhol com a Cidade Tracionada (na verdade, Londres) de Mortal Engines, ${ }^{9}$ série de novelas steampunk escrita por Philip Reeve (com previsão de chegar aos cinemas em Dezembro de 2018). Mas vamos nos ater às preocupações ambientais da investigação de Domingues ao invés de seu aspecto ficcional, já explorado em parágrafos anteriores. Enquanto o deslocamento da cidade de Herron tinha como princípio ativo a busca por recursos energéticos, a mobilidade das cidades de Domingues prevê a substituição integral de cidades estáticas não sustentáveis e o reflorestamento de áreas verdes devastadas por elas. O que se nota de pertinente nessa tarefa é a retomada da reflexão sobre o grau de impacto das grandes metrópoles sobre o meio ambiente, questão ao que parece secundária em qualquer plano diretor de grandes centros.

\section{Nova Kiruna}

A despeito da massa crítica imaginativa engendrada pela cultura popular, ainda não foi efetivamente erigida uma genuína "cidade andarilha". Mas havemos de reconhecer que, antes de implementá-las, é preciso imaginá-las - e daí a importância da quantidade de tinta consumida na elaboração de estereótipos. Em termos concretos, já foram registados casos de "relocalização estrutural", muitas vezes em grande escala, a maioria decorrente de atividades de mineração, sendo os casos mais famosos Hibbing, no estado norte-americano de Minnesota (1910) e Morococha, no Peru (2013). O exemplo mais recente e abstruso é o de Kiruna, pequena cidade de vinte mil habitantes fundada há cem anos no círculo ártico da Suécia com o intuito de abrigar os trabalhadores envolvidos na extração de minério de ferro, atividade administrada desde então pela empresa estatal LKAB (Luossavaara-Kiirunavaara Aktiebolag). Em uma análise do discurso dos que controlam a municipalidade é possível perceber substituições na linguagem do regime urbano, passando o deslocamento integral da cidade a ser chamado, nas notas para imprensa, de "reinvenção".${ }^{10}$ Artifícios eufemísticos estão sendo empregados igualmente para revogar antonomásias de um passado recente, como "a cidade deformada", expressão que remete ao processo de alteração tectônica provocada pela atividade extrativista da LKAB, o que na linguagem geotécnica da mineração é apontada como "deformação de superfície".

O plano de transferir a cidade tijolo por tijolo para outra localidade, chamado de forma confiante pela municipalidade de Kiruna 4-Ever, é detalhado em vídeo ${ }^{11}$ apresentado na Bienal de Arquitetura de Veneza de 2014. Há o entediamento de que não se trata de deslocar a cidade de um ponto para outro de um só golpe, como vislumbraram os 
12 Ver Ghilardi+Hellsten Arkitekter / White Architects em: $<$ https://www.ghilardihellsten. com/kiruna4ever>. Acesso em: 25 janeiro 2018

\begin{abstract}
13 Cientistas consideram que cidades da Ásia seriam as mais atingidas, mas isso não significa que as de outros continentes estariam a salvo. Ver infográficos em HOLDER, Josh; KOMMENDA, Niko; WATTS, Jonathan; et al. The three-degree world: cities that will be drowned by global warming. The Guardian, Disponível em: <http://www.theguardian. com/cities/ng-interactive/2017/ nov/03/three-degree-world-cities-drowned-global-warming $>$ Acesso em: 25 jan. 2018.
\end{abstract}

140 filme Mortal Engines já vem mobilizando a atividade conjectural de fãs com recursos intelectuais privilegiados, um dos quais calculou, analisando fotogramas do filme, a velocidade limite de uma cidade motora do porte de Londres: a velocidade aproximada seria de $26,4 \mathrm{~m} / \mathrm{s}$ (ou quase 96 $\mathrm{km} / \mathrm{h}$ ). Ver tabelas e detalhes em ALLAIN, Rhett. Let's do the Physics of the Giant Driving Cities in Mortal Engines. Wired, 2018. Disponível em: <https://www. wired. com/story/lets-do-the-physicsof-the-giant-driving-cities-inmortal-engines/>. Acesso em: 25 janeiro 2018. arquitetos radicais, e sim reconstruí-la paulatinamente em outra localidade - contudo as metáforas animistas se fazem presentes: "Ao deslocarmos a cidade inteira, Kiruna será literalmente um pouco como um milípede andante, movendo-se, rastejando-se lentamente alguns quilômetros para o leste", explica o arquiteto responsável Mikael Stenqvist. No vídeo, após Eva Ekelund (da Secretaria de Desenvolvimento Territorial) elucidar quais os riscos inerentes das zonas de deformação produzidas pela mineradora, somos informados de que o grande desafio será principalmente de cunho social, de como, por exemplo, colocar em debate democrático a permutação para alhures de marcos históricos da cidade, objetos públicos psicogeograficamente associados aos locais originais de sua edificação. No projeto da matriz estratégica, disposto no site do escritório ${ }^{12}$ vencedor da licitação, nota-se nos conteúdos que áreas-chave da cidade deverão "se mover gradualmente através de um processo passo a passo" em direção ao leste, gerando uma "espinha dorsal" de espaços públicos que "liga o antigo ao novo ... mantendo a cidade intacta através de sua mudança morfológica". A transposição completa, prevista para terminar em 2100, deverá transformar o "tecido antigo" à medida que a cidade avança organicamente, tendo como orientação projetual uma filosofia "holística".

Uma atividade econômica ordinária, como a mineração comercial, passa a ser o princípio motor de se deslocar uma cidade inteira (e, por conseguinte, a sua população), proeza pela qual foi escusada Joanesburgo, na Africa do Sul, condenada perpetuamente a não ter um sistema de transporte metroviário subterrâneo, em razão das deformações geofísicas decorrentes da inexorável atividade de mineração de ouro durante o século 19. Aparentemente as duas cidades são vítimas de atividades antropogênicas, sendo o caso questionar se a elevação de nível do mar, causado por mudanças climáticas - em igual medida antropogênicas - não colocaria em risco metrópoles costeiras de grande porte como Osaka, Hong Kong e Xangai. ${ }^{13}$ Não seria o caso, em tal contexto de urgência ambiental, reunir urbanistas e engenheiros mecânicos para concretizarem o sonho psicodélico de Ron Herron? Por certo que a relocalização estrutural de Xangai seria um tarefa infinitamente mais complexa de que arquitetar uma Nova Kiruna, e por isso talvez ela já esteja condenada, mas estamos falando de cidades futuras, a serem concebidas por gerações futuras. Aparentemente, o plano de se construir uma "cidade motorizada", na dimensão de uma cidade de menor porte, como a cidade de Dominguez, não é ao menos tão inverosímel sob a ponto de vista da ciência física. ${ }^{14}$ Reinações à parte, o desígnio de protagonistas do planejamento urbano que vivenciam o atual momento histórico deveria ser o de assentar, mais do nunca, um calço entre a fantasia e a concretude, entre a imaginação e a possibilidade de se fundar autênticas metrópoles beduínas.

\section{Referências bibliográficas}

APOLLONIO, Umbro. Futurist manifestos. Nova York: Viking Press, 1973.

MAJER, Zsuzsa; TELEKI, Krisztina. Monasteries and Temples of Bogdiin Khuree, Ikh Khuree or Urga, the Old Capital City of Mongolia in the First Part of the Twentieth Century. Budapeste: Eötvös Loránd University, 2006.

MUSIL, Robert. Homem Sem Qualidades, O. Edição: 1. Rio de Janeiro, RJ: Nova Fronteira, 1980.

NYSETH, Torill; VIKEN, Arvid. Place Reinvention: Northern Perspectives. Surrey: Ashgate Publishing, Ltd., 2012. 
RAKOWITZ, Michael; CHRISTOV-BAKARGIEV, Carolyn. Circumventions. Paris / Nova York: Onestar Press, 2003

RILEY, Terence; Museum of Modern Art (New York, N.Y.). The Changing of the Avant-garde: Visionary Architectural Drawings from the Howard Gilman Collection. Nova York: The Museum of Modern Art, 2002.

RUCKER, Rudy; SIRIUS, R.U.; MU, Queen. MONDO 2000: a User's Guide to the New Age. Nova York: HarperCollins Publishers, 1992

SHIRLEY, John. City Come A-Walkin'. Nova York: Simon and Schuster, 2014. 